\title{
WILEY-VCH
}

Copyright WILEY-VCH Verlag GmbH \& Co. KGaA, 69469 Weinheim, Germany, 2013. Supporting Information

\section{Microwave-assisted Silver Nanoparticle Film Formation for SERS applications}

Guido Soliveri, Silvia Ardizzone, Sezin Yüksel, Dana Cialla-May, J. Popp, Ulrich S. Schubert, Stephanie Hoeppener*

Guido Soliveri, Prof. Silvia Ardizzone

Dipartimento di Chimica, Università degli Studi di Milano, Via Golgi 19, 20133 Milano, Italy Sezin Yüksel, Dr. Dana Cialla-May, J. Popp

Leibniz-Institut of Photonic Technology, Albert-Einstein-Str. 9, 07745 Jena, Germany;

Institute of Physical Chemistry and Abbe Center of Photonics, Friedrich Schiller University Jena, Helmholtzweg 4, 07743 Jena, Germany

Prof. Dr. Ulrich S. Schubert, Dr. Stephanie Höppener

Laboratory of Organic and Macromolecular Chemistry (IOMC), Friedrich Schiller University Jena, Humboldtstr. 10, 07743 Jena, Germany and Jena Center for Soft Matter (JCSM), Friedrich Schiller University Jena, Philosophenweg 7, 07743 Jena, Germany 


\section{WILEY-VCH}

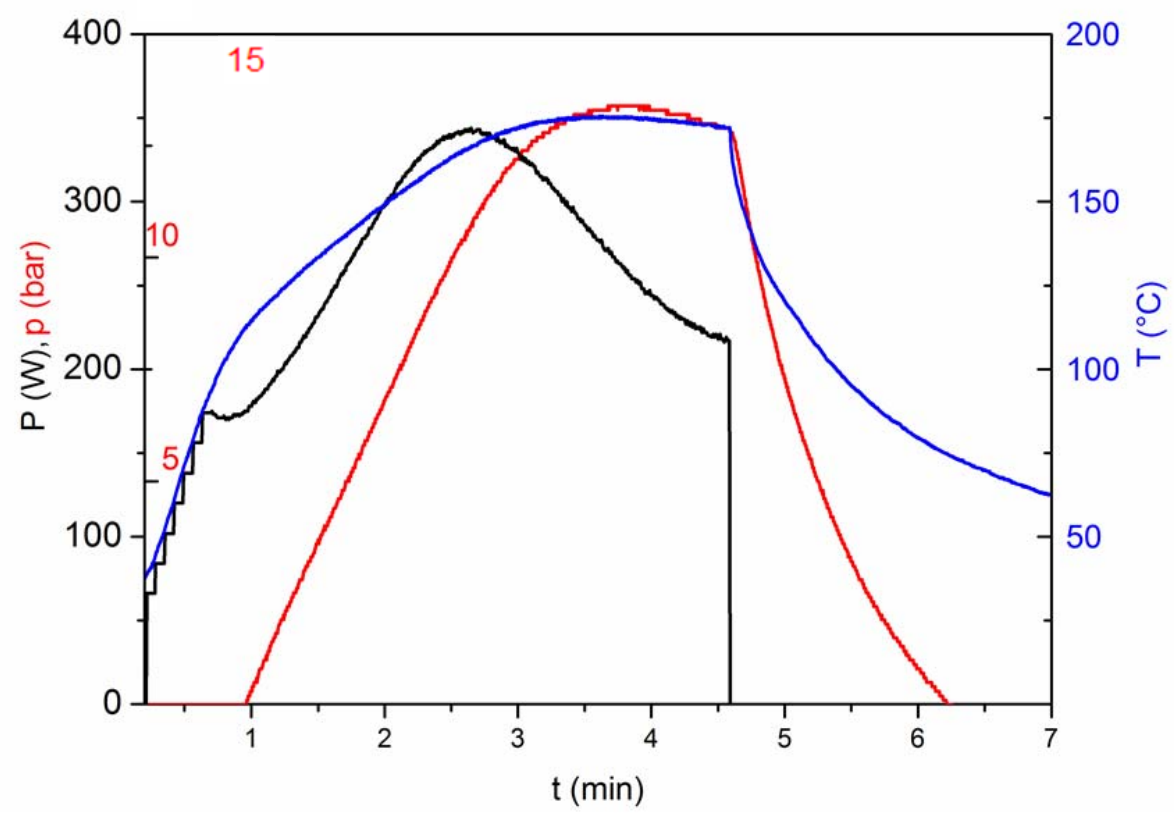

Figure S1: Pressure (p) / power (P) / temperature (T) plot vs. time of irradiation of the sample obtained after two minutes at $170^{\circ} \mathrm{C}$, using ethanol as the reducing agent.

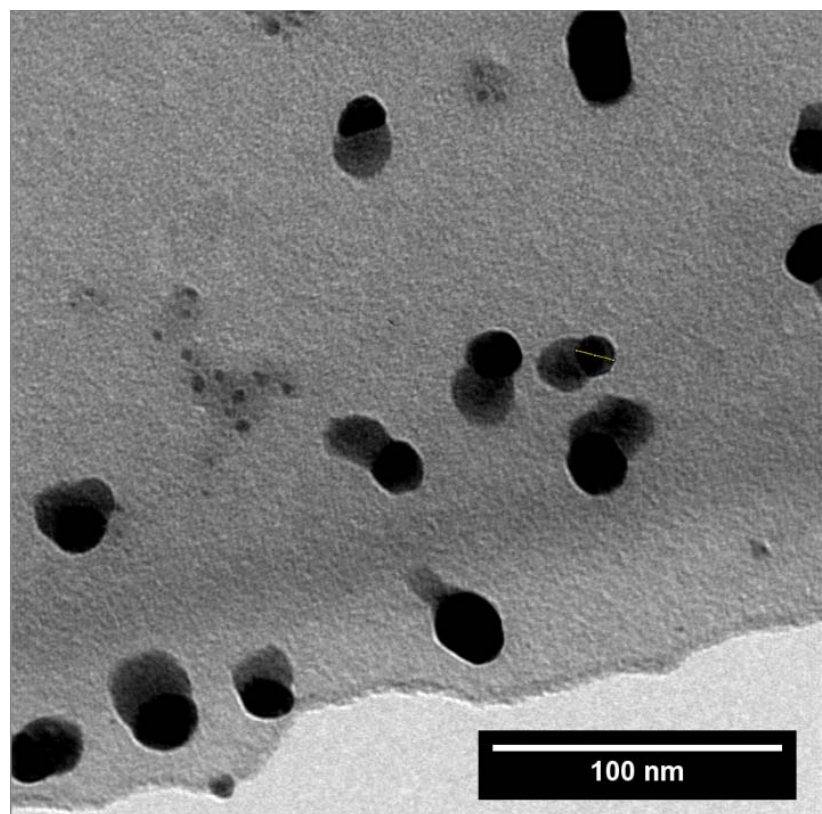

Figure S2: TEM picture obtained by blotting the final solution directly on the TEM grid. Sample obtained after two minutes of irradiation at $170{ }^{\circ} \mathrm{C}$ using ethanol as reducing agent. 


\section{WILEY-VCH}

\section{Choice of experimental conditions: Temperature and amount of reactants}

The choice of the specific conditions to be adopted was first investigated. The role of temperature, the dependence of the Ag salt concentration and the amount of reducing agent are here summarized.

\section{Temperature}

The temperature range between 150 to $190{ }^{\circ} \mathrm{C}$ was investigated. The synthesis was planned in such a way to heat the reaction mixture for two minutes at a constant desired temperature. Figure S3 shows the UV/vis spectra of the sample heated at 150, 170, 180 and $190^{\circ} \mathrm{C}$, while Figure S4 shows the SEM top-view pictures of the corresponding samples. In the case of the sample heated at $150^{\circ} \mathrm{C}$, no clear-cut plasmonic resonance was observed. The other samples revealed a similar peak position, with a slight blue-shift associated with increasing temperature. SEM pictures of the $150{ }^{\circ} \mathrm{C}$ sample displayed agglomerates attached to the surface. The sample at $170{ }^{\circ} \mathrm{C}$ was homogeneous, with quite small, well packed particles at the surface. By increasing the temperature, the particles grew and the layer became less homogeneous and less packed. The chosen temperature of $170{ }^{\circ} \mathrm{C}$ was a good compromise between plasmonic resonance and desired properties at the surface.

Amount of silver acetate and ethanol

We optimized the silver acetate / water + ethanol / water ratios in such a way to obtain the best film. The conditions reported in the manuscript $(1 \mathrm{~mL}$ of ethanol, $2 \mathrm{~mL}$ of water and 1 mg of silver acetate) were chosen on the grounds of the investigation of syntheses carried out changing the concentrations of ethanol and silver salt. In the case of a lower amount of ethanol (0.5 mL), no film formation was observed. Figure S5 shows SEM pictures of films obtained by utilizing different reaction mixtures. We evaluated by electron microcopy and observation with the bare eye the best condition for our purpose. As shown in Figure S5, only in (c) the particles were rather spherical and well packed. 


\section{WILEY-VCH}

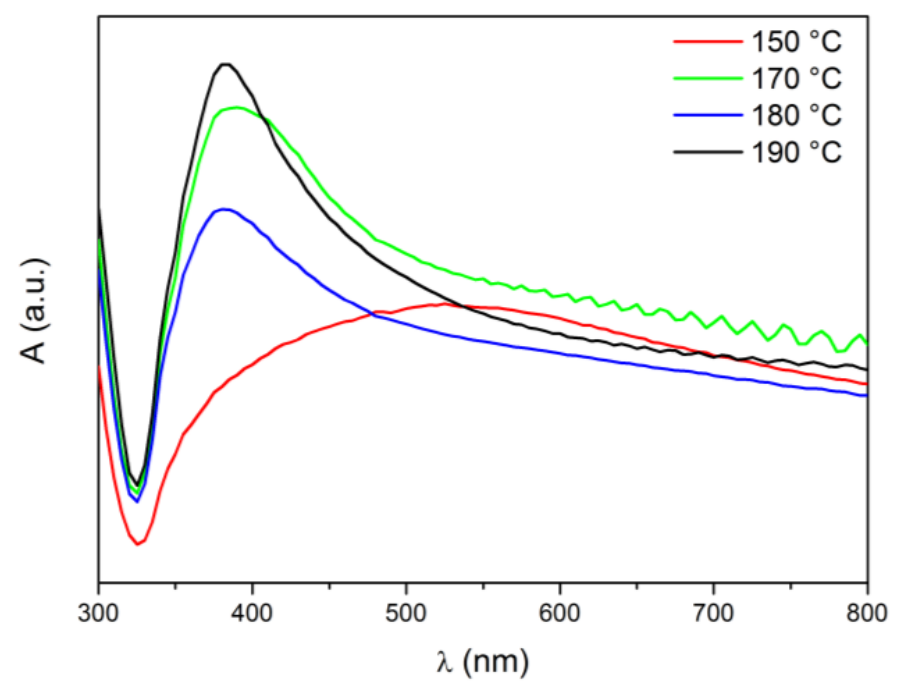

Figure S3: UV-vis spectroscopy of the sample obtained after two minutes at different temperatures using ethanol as reducing agent.
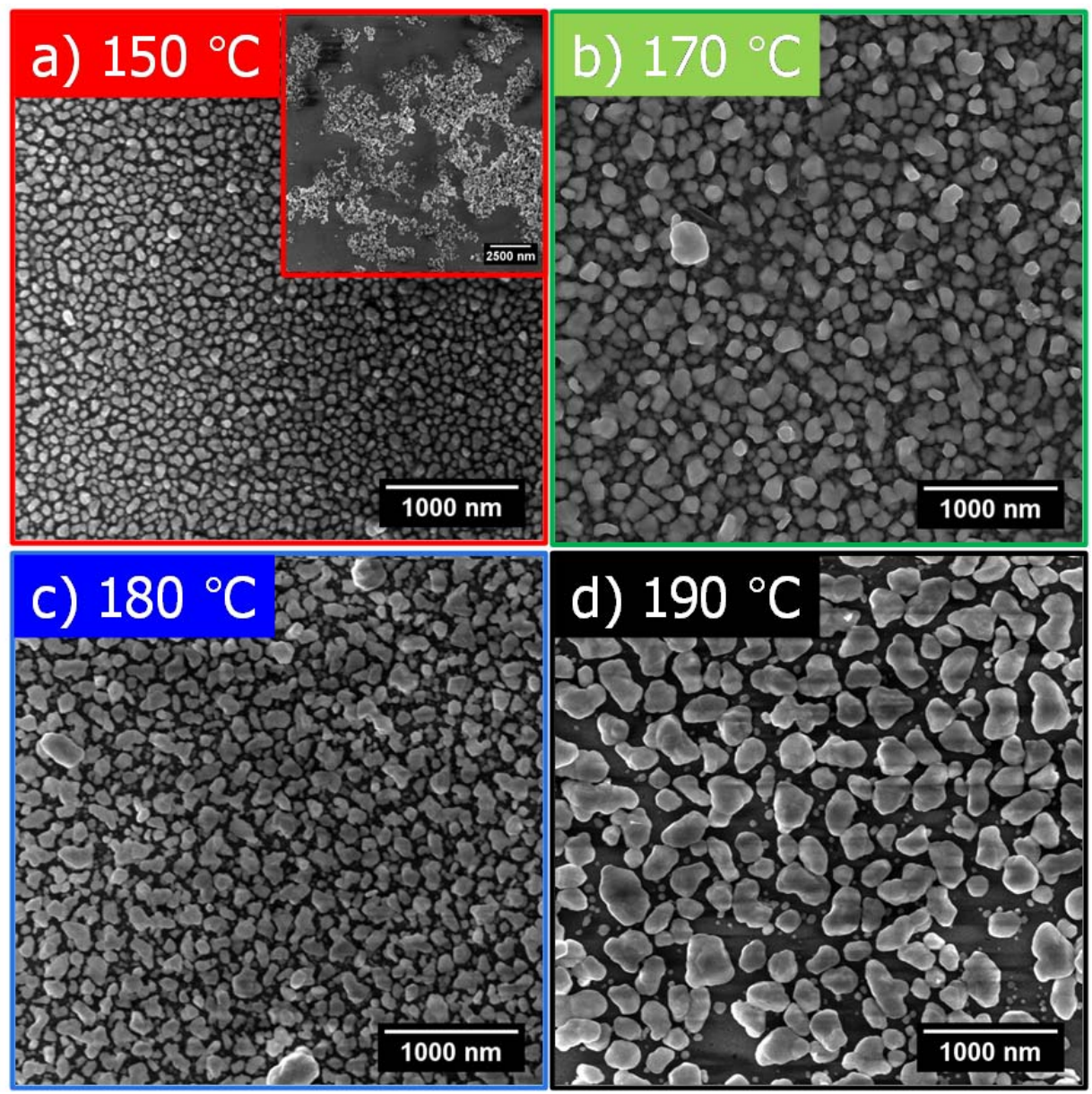

Figure S4: SEM of the samples obtained after two minutes at different temperatures, using ethanol as reducing agent. 


\section{WILEY-VCH}
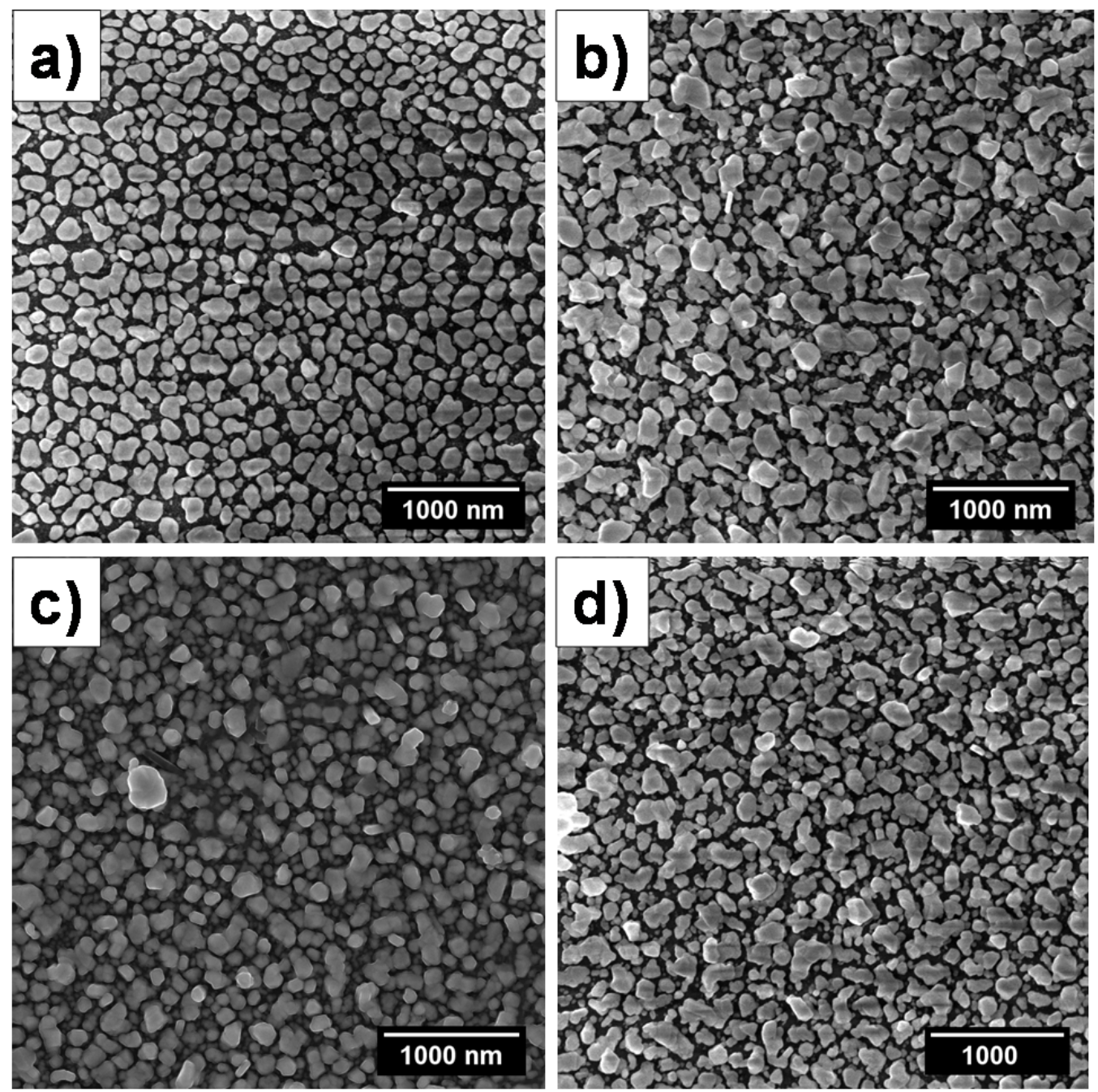

Figure S5: SEM of the samples obtained after two minutes at $170{ }^{\circ} \mathrm{C}$ : (a) $0.5 \mathrm{mg}$ and (b) 1.5 mg of Ag acetate on $1 \mathrm{~mL}$ of ethanol; (c) $1 \mathrm{mg}$ of Ag acetate and 1mL of ethanol; (d) $1 \mathrm{mg}$ of Ag acetate and $1.5 \mathrm{~mL}$ of ethanol.

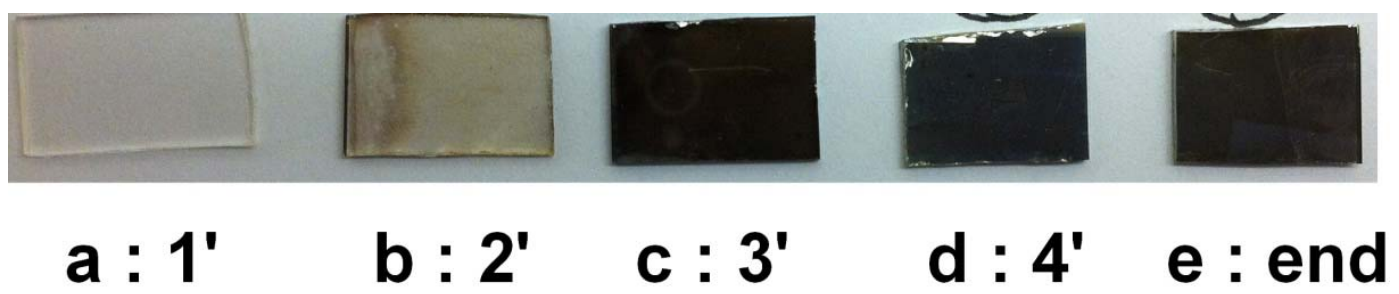

Figure S6: (a-d) Photograph of the samples in which the reaction was quenched after 1, 2, 3 or 4 minutes from the beginning of the MW irradiation and (e) of the film at the end of the optimized reaction (two minutes at $170{ }^{\circ} \mathrm{C}$ ). 


\section{WILEY-VCH}

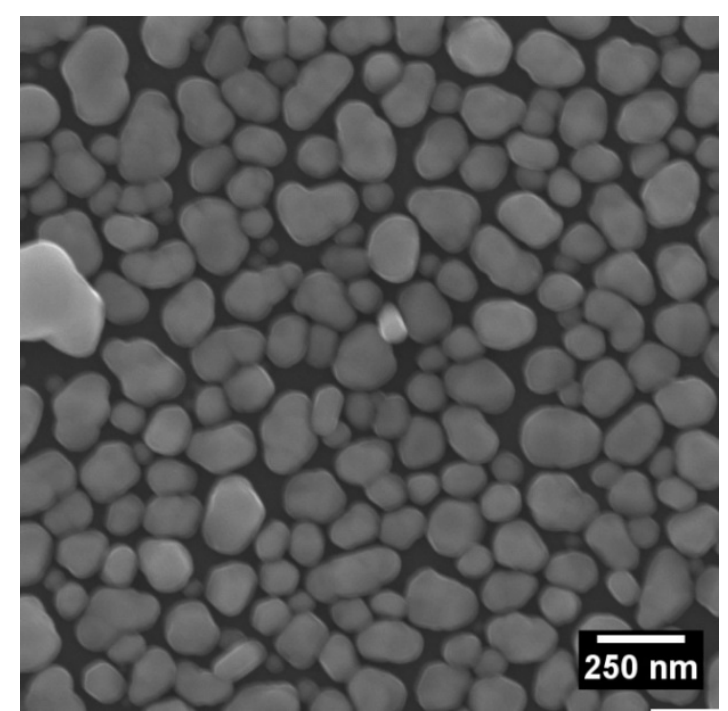

Figure S7: SEM of the sample obtained after 10 minutes at $170{ }^{\circ} \mathrm{C}$ using ethanol as reducing agent.

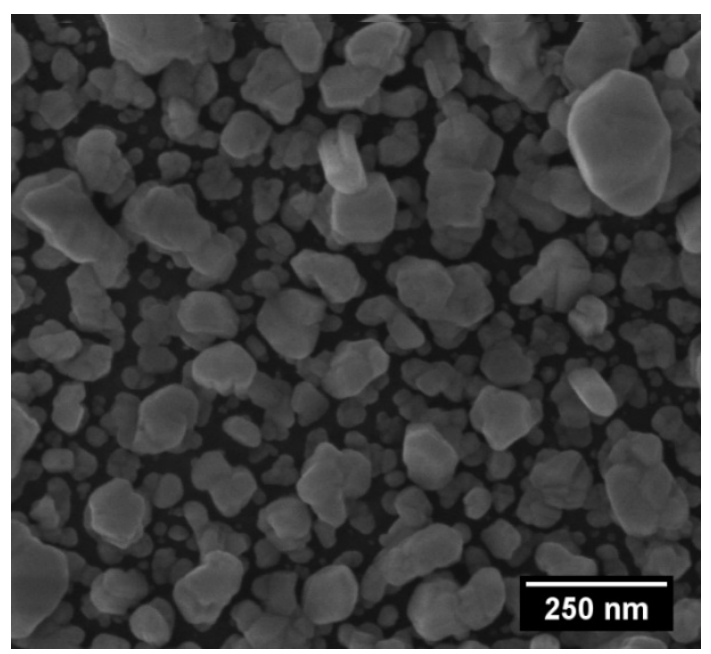

Figure S8: SEM of the sample obtained after two minutes at $170{ }^{\circ} \mathrm{C}$, using ethanol as the reducing agent (magnification). 


\section{WILEY-VCH}

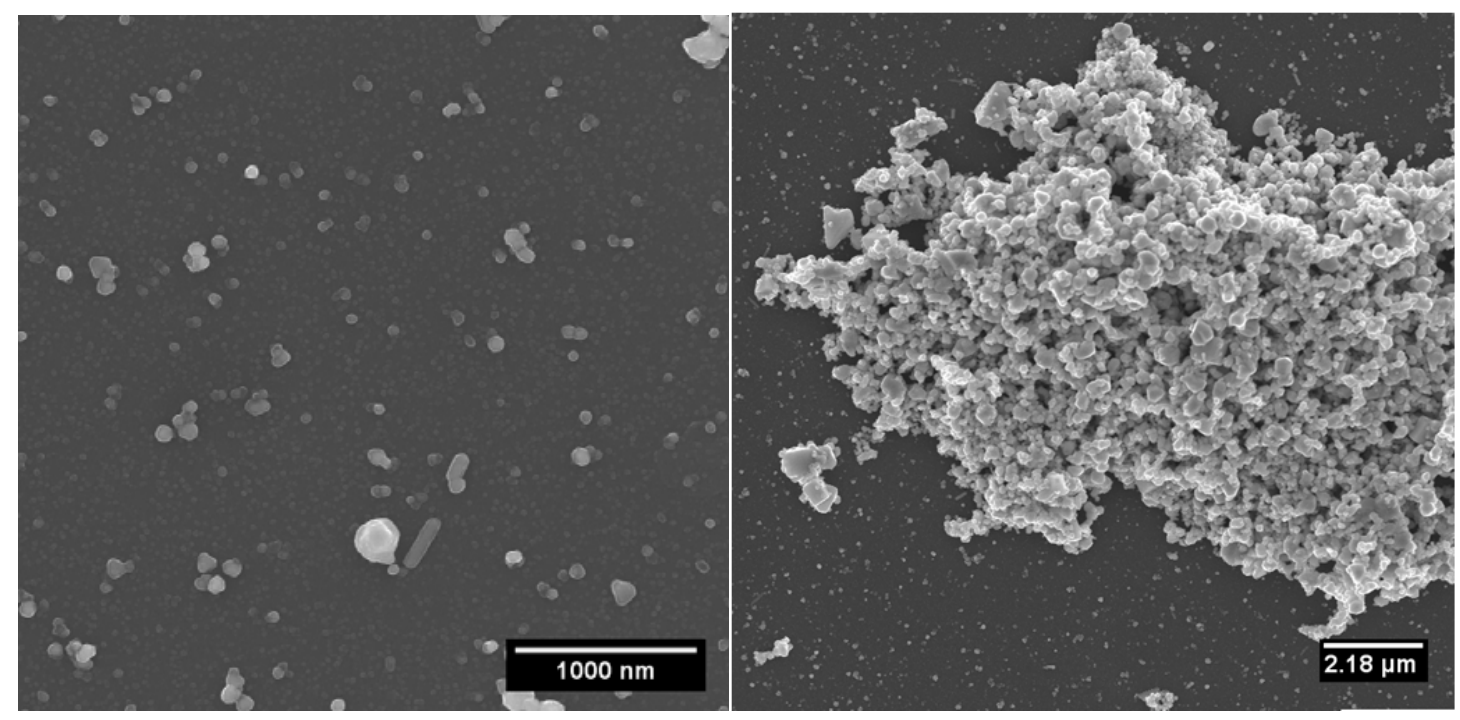

Figure S9: SEM of the sample obtained after two minutes at $170{ }^{\circ} \mathrm{C}$ using ethylene glycol as the reducing agent; two different areas.

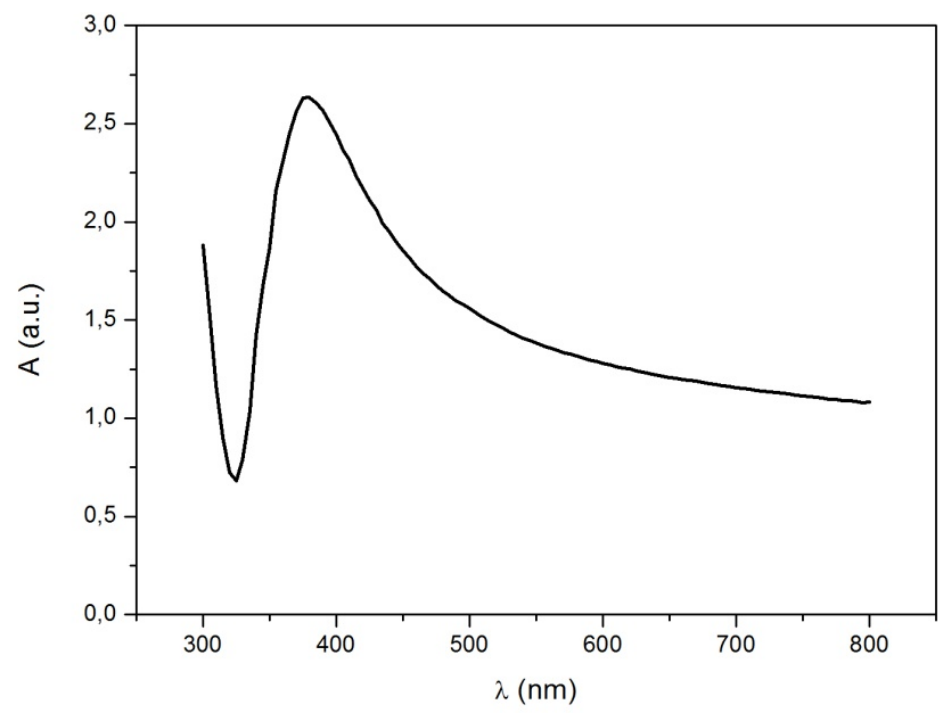

Figure S10: UV-Vis spectroscopy of the sample obtained after two minutes at $170{ }^{\circ} \mathrm{C}$, using ethanol as the reducing agent on a hydrophobic silanized glass lamina as a support. 
WILEY-VCH

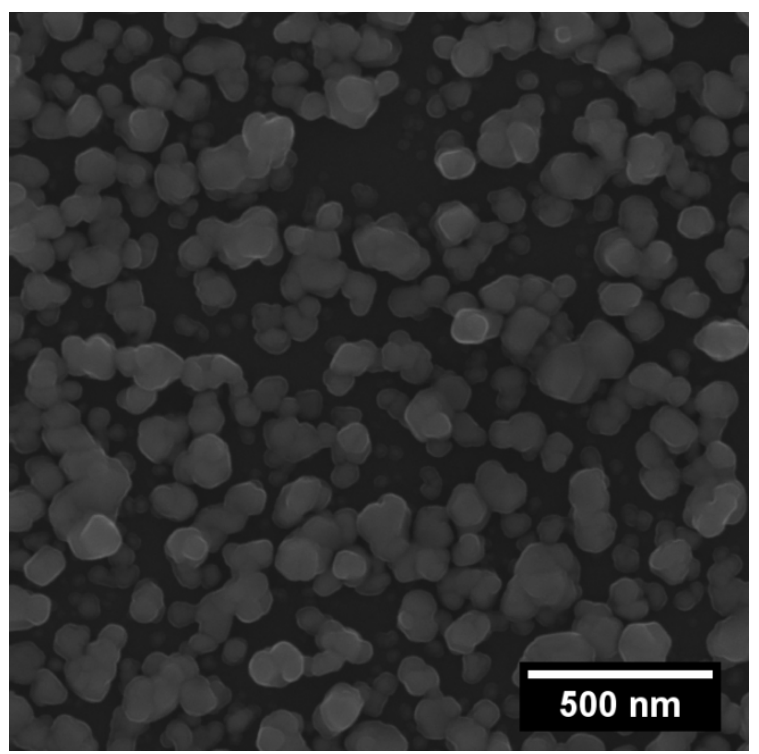

Figure S11: SEM of the sample obtained after 2 minutes at $170{ }^{\circ} \mathrm{C}$, using ethanol as the reducing agent an a hydrophobic silanized glass lamina as a support.

Table T1.

\begin{tabular}{lccc}
\hline & Ethanol & Ethylene glycol & Glycerol \\
\hline Viscosity / cP & 12 & 161 & 1412 \\
$\begin{array}{l}\text { Boiling point } \\
/{ }^{\circ} \mathrm{C}\end{array}$ & 78 & 197 & 290 \\
Density / $\mathrm{kgL}^{-1}$ & 0.789 & 1.113 & 1.261 \\
$\begin{array}{l}\text { Dielectric } \\
\text { constant }\end{array}$ & 24 & 37 & 42 \\
$\begin{array}{l}\text { Surface } \\
\text { tension / } \\
\mathrm{nMm}\end{array}$ & 22 & 48 & 63 \\
\hline
\end{tabular}

